\title{
Recommending a Book with a Chapter Reviewing Innovative Approaches of Solar Cell Research
}

\section{Jianming Li}

Institute of Semiconductors, Chinese Academy of Sciences, Beijing, China.

Email: jml@semi.ac.cn

Received January $14^{\text {th }}, 2013$; revised February $16^{\text {th }}, 2013$; accepted February $25^{\text {th }}, 2013$

\begin{abstract}
This article is a brief description of some innovative approaches presented in Chapter 6 of a book entitled "Solar Cell Research Progress". One approach is a novel superficial modification technique which offers a new opportunity to fabricate low cost solar cells by using silicon materials with the lowest possible purity. The other approach is a V-shaped module (VSM) technique which enables an obvious increase of the efficiencies for silicon solar cells.
\end{abstract}

Keywords: Silicon; Solar Cells; VSM; Infrared Emission

It is known that nature of war is to plunder limited earth resources, and the development of energy resources has become essential for economy. Renewable photovoltaic (PV) solar energy is a promising alternative energy source for the future, due to the global climate change and world's limited traditional energy resources such as fossil, nuclear, and petroleum fuels. The fact that clean solar energy is free does not mean that it will automatically have a low cost of application. A lot of studies have been underway in order to economically extract the green-energy through solar cells from the inexhaustible resource that is available anywhere in the world. Up to now, the economical use of PV solar cells is still a dream. Every possible effort should be worth the risk in order to make the dream come true. The following is a brief description of some innovative approaches presented in Chapter 6 of a book entitled "Solar Cell Research Progress" [1].

Silicon is the second-most abundant element in the earth's crust. Silicon solar cell manufacturing can be developed without the toxicity or resource availability issues, which meets the requirements of manufacturing volume enough for the whole mankind. Since silicon solar cell modules cost 4 - 5 dollars per watt, which can produce electricity at a rate of 25 - 30 cents per kilowatthour (kWh), a factor of about 5 in cost reduction is required to make the solar cell modules produce electricity at the present cost of electricity generated by the traditional energy resources.

Two different approaches are key issues and have been developed in an attempt to reduce the cost of electricity generated by solar cells. The first is to raise the power conversion efficiency $(\eta)$ of solar cells. However, there is a thermodynamic limit for raising $\eta$ of solar cells. The second type of approach is to reduce the costs of solar cell materials. Although solar grade silicon (SG-Si) used for fabricating commercial solar cells can have three or four orders of magnitude more impurities than the electrical grade silicon (EG-Si) used for making integrated circuits (IC), the purity of SG-Si is still quite high. For any material, high purity implies high cost, as is well known. The cost of electricity generated by solar cells can probably be greatly reduced if cells based on very low purity silicon can be made to operate with acceptably lower efficiencies. There appears to be plenty of potential for developing the second approach. The major technical challenge will be finding a low-cost way to convert very low purity silicon (e.g., metallurgical grade silicon at a price of about $\$ 1 / \mathrm{kg}$ ) into a material suitable for solar cell production.

At the end of the 1980s, an idea of silicon on defect layer (SODL) was proposed. The experimental results achieved at Brookhaven and Sandia National Laboratories, USA, and the Chinese Academy of Sciences have demonstrated that the SODL approach leads to a novel superficial modification which offers a new opportunity to fabricate solar cells by using silicon materials with the lowest possible purity. If the SODL procedure is in combination with a plasma immersion ion implantation technique, there appears to be great potential for obtaining extremely inexpensive solar cells fabricated by using very low purity silicon. From a cost estimate, it is possible for the SODL technique to achieve PV energy cost at a level of 7 cents/(kWh) which is comparable with the 
present cost of electricity generated by traditional energy resources. Moreover, the SODL technique has the potential to extend its concept from silicon to other kinds of impure materials for solar cell fabrication.

In addition, A V-shaped module (VSM) technique enables an obvious increase of the efficiencies for silicon solar cells. In the VSM, a fraction of incident energy into each cell under illumination is converted into output electric power, and the surplus energy is released from the cell, mainly as infrared (IR) emission, under the constraint of energy conservation. Each cell is a "second" source of incoming energy for the opposite cell, and the two cells enhance each other equally. Compared to a conventional flat panel, the VSM has an additional opportunity to absorb light. Defects in each cell of the VSM could lead to the absorption of the emitted IR photons through sub-band-gap-excitation processes, and such absorption is proposed to explain the measured increases in efficiency. Among all kinds of materials, the used silicon wafers contain fewer defects than anyone of the other kinds of materials. This VSM technique is therefore proposed to improve the solar cells fabricated by using many kinds of materials and even to be a candidate for a common technique boosting efficiencies of various non-silicon solar cells. The VSM technique makes only a change from a flat panel to a V-shaped configuration. It is very easy to test the VSM effect by using any kind of already existing solar cells.

Also, a VSM-array forms a three-dimensional (3D) PV structure. The experimental data achieved at Massachusetts Institute of Technology, USA have demonstrated that 3D PV structures can generate measured energy densities (energy per base area, $\mathrm{kWh} / \mathrm{m}^{2}$ ) higher by a factor of $2-20$ than flat PV panels [2], which verifies the VSM effect. The VSM technique not only offers opportunities to develop space and concentrator cells, but also could find an application as a highsensitivity photodetector. Moreover, a VSM-array offers opportunities to increase generation power densities in area-limited applications such as solar-powered vehicles, boats, and aircrafts, etc. Figure 1 is the image of a solar car with the VSM technique (The picture is made by using 3D Max software). The 3D solar cell system (VSM

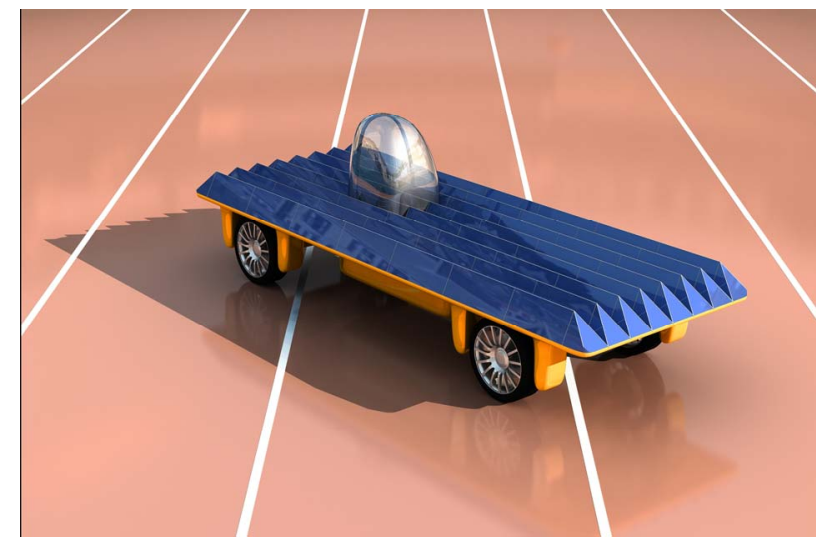

Figure 1. The image of a solar car with the VSM technique (the picture is made by using 3D Max software).

technique) is also proposed to be used in the Swiss solar plane in order to complete the mission of a round-theworld flight.

On the other hand, there appears to be potential for reducing the cost of many kinds of commercial solar cells. For example, it is possible to achieve PV energy cost at a level of 7 cents/(kWh) through developing silicon solar cells fabricated by using low purity silicon (e.g., metallurgical grade silicon at a price of about $\$ 1 / \mathrm{kg}$ ). In fact, the price of silicon solar cells has been greatly reduced for years. The decrease of silicon cell price from $19 \$ / \mathrm{W}$ in 1980 to about 3.5\$/W at present means an average price reduction by about $7 \%$ per year, and the price is predicted to be about $\$ 1 / \mathrm{W}$ in 2040 or beyond. In the fullness of time, solar cells can be very cheap, making the VSM-array a more promising technique.

\section{REFERENCES}

[1] J. Li, “A Candidate for Very Low Cost Solar Cells: Solar Cells Based on Low-Purity Silicon Materials,” In: J. A. Carson, Ed., Solar Cell Research Progress, Nova Science Publishers, New York, 2008, pp. 259-275.

[2] M. Bernardi, N. Ferralis, J. H. Wan, R. Villalon and J. C. Grossman, "Solar Energy Generation in Three Dimensions,” Energy \& Environmental Science, Vol. 5, 2012, pp. 6880-6884. 